\title{
Review \\ Chemotherapy for malignant pleural mesothelioma: past results and recent developments
}

\author{
S Tomek ${ }^{*, 1}$, S Emri ${ }^{2}, K_{\text {Krejcy }}{ }^{3}$ and C Manegold ${ }^{4}$ \\ 'Department of Medicine I, Clinical Division of Oncology, Vienna, Austria; ${ }^{2}$ Department of Chest Disease, Hacettepe University School of Medicine, \\ Ankara, Turkey; ${ }^{3}$ Eli Lilly Regional Operations GesmbH Area Medical Centre, Vienna, Austria; ${ }^{4}$ Clinical Division of Oncology, Department of Medicine, \\ Thoraxklinik Heidelberg, Germany
}

\begin{abstract}
This review summarises the results of previously conducted clinical trials, and subsequently presents data arising from all phase II - III studies on chemotherapy of malignant pleural mesothelioma (MPM) published since the last relevant overview. While response rates exceeding 30\% have barely been achieved with established cytotoxic drugs in MPM therapy, novel chemotherapeutic agents and their combinations appear more promising. This applies especially to the antimetabolites, and in particular to pemetrexed that produced response rates of up to $45 \%$ in combination with platinum compounds. Raltitrexed combined with oxaliplatin has also been shown to be effective, and gemcitabine - applied as a single agent or in combination with cisplatin - as well as vinorelbine appear to improve the quality of life in patients presenting with MPM. Data can now be more precisely analysed by increasingly implemented randomised studies, applying a standardised staging system, and distinguishing prognostic groups. While chemotherapy for MPM remains a challenging task, important steps have clearly been made in the past years to combat this aggressive disease. The publication of pemetrexed with cisplatin phase III results in a peer-reviewed journal may soon establish a standard of care.
\end{abstract}

British Journal of Cancer (2003) 88, 167 - 174. doi:I0.1038/sj.bjc.6600673 www.bjcancer.com

(C) 2003 Cancer Research UK

Keywords: malignant pleural mesothelioma; chemotherapy

Although MPM aetiology is well known, therapeutic success with this disease has been unsatisfactory. Standard malignant pleural mesothelioma (MPM) therapy is still deficient, and decisions for surgical, radiotherapy or multimodal procedures are made on a case-by-case basis. In the majority of cases, a palliative treatment approach remains the only choice. The possibilities to resect MPM curatively are rare and only given in early-stage disease. Yet even at this point, resection is a matter of dispute because of historically high morbidity and mortality rates, relapse tendencies and disappointing long-term survival rates (Rusch and Venkatraman, 1996; Boutin et al, 1998). Irradiation for MPM assists in repelling tumour growth and temporarily relieving pain, but not attaining appreciably lengthened overall survival time (Kutcher et al, 1987; Soubra et al, 1990; Bissett et al, 1991). There is also no clear evidence that multimodality protocols involving surgery, radiotherapy and chemotherapy can improve survival (Antman et al, 1980; Hilaris et al, 1984; Linden et al, 1996). Although success in MPM chemotherapy has been limited, it now gives rise to promise by the use of an established and standardised staging system, with consideration given to prognostic factors and development of novel cytostatic agents.

\footnotetext{
*Correspondence: Dr S Tomek, Department of Medicine I, Clinical Division of Oncology, University Hospital Vienna, Waehringer Strasse I820, A- 1090 Vienna, Austria; E-mail: Sandra.Tomek@akh-wien.ac.at Received 15 May 2002; revised 30 September 2002; accepted 9 October 2002
}

\section{ROLE OF CHEMOTHERAPY}

Chemotherapy for MPM continues to be challenging. A multitude of cytotoxic drugs have been tested both as single agents and in combination chemotherapy regimens. The rates of objective tumour regression have only been between 10 and 30\% with cytotoxic monotherapy, having no significant impact on median survival. Combination chemotherapy has shown no clear advantage over single-agent therapy (Linden et al, 1996).

The evaluation of systemic chemotherapy in MPM has been problematic for several reasons. Owing to the rarity of this disease, only a few randomised studies based on large numbers of participants have been implemented to provide statistically significant statements regarding response to a particular therapy.

Furthermore, inadequate imaging procedures and nonuniform staging systems have complicated data interpretation. As performed in early studies, restaging by means of chest radiography failed to determine response to a given therapy accurately. Response rates have been more reliable since CT scanning has been recognised as a diagnostic tool. In 1995, the International Mesothelioma Interest Group (IMIG) proposed a novel TNM staging system, which was designed to record data concerning the natural history of the disease and was validated in two large surgical series of mesothelioma patients (Rusch and Venkatraman, 1996; Pass et al, 1998). The universal application of this system has ever since allowed for a more prudent evaluation of results emerging from clinical studies (Pass et al, 1998; Steele and Rudd, 2000).

Early clinical trials of MPM patients included heterogeneous groups of patients with divergent risk factors and were therefore 
often not powerful enough in assessing therapeutic efficacy of a particular treatment. In 1998, the European Organization for Research and Treatment of Cancer (EORTC) identified several prognostic variables for the course of the disease. In a multivariate analysis of the EORTC, poor prognosis was associated with the sarcomatous histologic subtype, male gender, poor performance status and a high white blood cell count (Curran et al, 1998). Likewise, the Cancer and Leukemia Group B (CALGB) analysed several pretreatment factors pooled from seven phase II studies that were predictive of poor survival and defined six prognostic groups. Poor prognosis was seen in patients with the following criteria: age older than 75 years, poor performance status, chest pain, dyspnoea, weight loss, high white blood cell count, elevated platelet count, low haemoglobin, elevated serum lactate dehydrogenase levels, pleural effusion and nonepithelial histology.

Owing to the establishment of prognostic scoring systems, identification of risk groups facilitated improved study design by evaluating more homogeneous patient groups or risk-group stratification in the course of randomisation (Curran et al, 1998).

The following sections summarise conventional single-agent and combination chemotherapy strategies. Results emerging from recent clinical studies with novel cytotoxic agents and their combinations are then presented, which have been published since the last review of chemotherapy in MPM.

Tables 1 - 3 summarise phase II - III single-agent and combination chemotherapy trials for MPM including more than 15 patients, which have been conducted since 1995.

\section{Single-agent chemotherapy}

Doxorubicin is the most frequently investigated chemotherapeutic agent in the treatment of MPM. Studies have failed to corroborate evidence, however, for encouraging response rates to doxorubicin of up to $20 \%$ that had been reported in earlier studies (Aisner and Wiernik, 1981; Antman and Corson, 1985). Likewise, newer anthracyclines such as epirubicin, detorubicin, pirarubicin and mitoxantrone have shown low levels of efficacy and have offered no clinically relevant advantage over doxorubicin (Colbert et al, 1985; Eisenhauer et al, 1986; Sridhar et al, 1989; Kaukel et al, 1990; Magri et al, 1991; van Breukelen et al, 1991; Mattson et al, 1992; Magri et al, 1992). In summary, the overall response rate produced by anthracyclines applied in MPM appears to be no higher than $15 \%$ and median survival does not exceed 8 months.

Apart from anthracyclines, several studies have investigated the platinum compounds, cisplatin and carboplatin. Single-agent cisplatin resulted in a response rate of merely $14.3 \%$ and a median survival of 7.5 months (Zidar et al, 1988). Studies using the newer compound carboplatin resulted in similar response rates ranging between 6 and 16\% (Mbidde et al, 1986; Raghavan et al, 1990; Vogelzang et al, 1990).

The alkylating agents cyclophosphamide and mitomycin have shown low-level activity in MPM therapy (Bajorin et al, 1987; Sorensen et al, 1985). Promising results initially arising from high-dose ifosfamide therapy (Alberts et al, 1988) could not be confirmed by subsequent studies (Falkson et al, 1992; Zidar

Table I Series of $\geqslant 15$ patients with MPM treated with single-agent chemotherapy since 1995

\begin{tabular}{|c|c|c|c|c|c|c|}
\hline \multirow[b]{2}{*}{ Single agent } & \multirow{2}{*}{$\begin{array}{l}\text { First author } \\
\text { (year) }\end{array}$} & \multirow{2}{*}{$\begin{array}{l}\text { No. of } \\
\text { patients }\end{array}$} & \multicolumn{2}{|c|}{ Responders } & \multirow{2}{*}{$\begin{array}{l}\text { 95\% confidence } \\
\text { interval }(\%)\end{array}$} & \multirow{2}{*}{$\begin{array}{l}\text { Median survival } \\
\text { (months) }\end{array}$} \\
\hline & & & No & $\%$ & & \\
\hline \multicolumn{7}{|c|}{ Anthracyclines and related compounds } \\
\hline Liposomal doxorubicin & Baas (2000) & 32 & 2 & 6 & $0-20$ & 13 \\
\hline Liposomal doxorubicin & $\mathrm{Oh} /(2000)$ & 24 & 0 & 0 & na & 9.3 \\
\hline Liposomal danaurubicin & Steele (1998) & $\mid 1$ & 0 & 0 & na & 6.1 \\
\hline \multicolumn{7}{|l|}{ Platinum compounds } \\
\hline ZD0473 & Giaccone (200I) & 10 & Two regres & le disease & na & na \\
\hline \multicolumn{7}{|l|}{ Alkylating agents } \\
\hline Ifosfamide & Andersen (1999) & 26 & । & 4 & $0-11$ & 10 \\
\hline Etoposide i.v. & Sahmoud (1997) & 49 & 2 & 4 & $1-15$ & 7.3 \\
\hline Etoposide p.o. & Sahmoud (1997) & 45 & 3 & 7 & $2-20$ & 9.5 \\
\hline \multicolumn{7}{|c|}{ Topoisomerase interactive agents } \\
\hline \multicolumn{7}{|c|}{ Campthotecin analogues } \\
\hline Irinotecan & Kindler (2000) & 28 & 0 & 0 & $10-55$ & 7.9 \\
\hline & Maksymiuk (1998) & 22 & 0 & 0 & na & 8 \\
\hline \multicolumn{7}{|c|}{ Antimicrotubule agents } \\
\hline \multicolumn{7}{|c|}{ Vinca alcaloids } \\
\hline Vinorelbine & Steele $(2000)$ & 64 & 12 & 21 & $10-44$ & 13.4 \\
\hline Vincristine & Martensson (1989) & 23 & 0 & 0 & $0-14$ & 7 \\
\hline Vinblastine & Cowan (1988) & 20 & 0 & 0 & $0-16$ & 3 \\
\hline \multicolumn{7}{|l|}{ Taxanes } \\
\hline Docetaxel & Belani (1999) & 19 & I & 5 & $0-26$ & na \\
\hline Docetaxel & Vorobiof (2000) & 22 & 3 & 14 & $7-46$ & 12 \\
\hline Paclitaxel & v. Meerbeck (1996) & 25 & 0 & 0 & $0-15$ & 9.8 \\
\hline Paclitaxel & Vogelzang (1999) & 35 & Three regre & ble disease & $2-10$ & 5 \\
\hline \multicolumn{7}{|l|}{ Antimetabolites } \\
\hline Edatrexate & Kindler (1999) & 20 & 5 & 25 & $9-49$ & 9.6 \\
\hline Edatrexate+LV-rescue & Kindler (1999) & 38 & 6 & 16 & $6-31$ & 6.6 \\
\hline Gemcitabine & Kindler (200I) & 17 & 0 & 0 & $3-13$ & 4.1 \\
\hline Gemcitabine & van Meerbeck (1999) & 27 & 2 & 7 & $1-24$ & 8 \\
\hline Gemcitabine & Bischoff (1998) & 16 & 5 & 31 & na & na \\
\hline Pemetrexed & Scagliotti (200I) & 62 & 9 & 6 & na & 10.7 \\
\hline
\end{tabular}

na=not applicable. 
Table 2 Series of $\geqslant 15$ patients with MPM treated with combination chemotherapy since 1995

\section{Responders}

\begin{tabular}{|c|c|c|c|c|c|c|}
\hline Agent & First author (year) & No. of patients & No. & $\%$ & $95 \%$ confidence interval $(\%)$ & Median survival \\
\hline Doxorubicin+cisplatin+mitomycin & Pennucci (1997) & 23 & 5 & 21 & $7-42$ & 11 \\
\hline Doxorubicin+cisplatin+mitomycin+bleomycin & Breau $(1991)$ & 25 & 11 & 44 & $27-63$ & na \\
\hline \multicolumn{7}{|l|}{ Cisplatin-containing combinations } \\
\hline Cisplatin+DHAC & Samuels (1998) & 29 & 5 & 17 & $5-30$ & 6.4 \\
\hline Cisplatin+etoposide & Eisenhauer (1988) & 26 & 3 & 12 & $4-30$ & na \\
\hline Cisplatin+Irinotecan & Nakano (1999) & 15 & 4 & 27 & $8-55$ & 7.1 \\
\hline Cisplatin+mitomycin+vinblastine & Middleton (1998) & 39 & 8 & 20 & na & 6 \\
\hline Cisplatin+pemetrexed (phase I) & Thodtman (1999) & II & 5 & 45 & na & na \\
\hline Cisplatin+paclitaxel & Fizazi $(2000)$ & 18 & । & 6 & $0-24$ & 12 \\
\hline \multicolumn{7}{|l|}{ Other combinations } \\
\hline Methotrexate+mitoxantrone+mitomycin & Pinto (200I) & 22 & 6 & 32 & $|2-5|$ & 13.5 \\
\hline
\end{tabular}

na=not applicable.

Table 3 Series of randomized phase II - III studies in patients with MPM treated with chemotherapy

\begin{tabular}{|c|c|c|c|c|c|c|}
\hline \multirow[b]{2}{*}{ Agent } & \multirow{2}{*}{$\begin{array}{l}\text { First author } \\
\text { (year) }\end{array}$} & \multirow{2}{*}{$\begin{array}{c}\text { No. of } \\
\text { patients }\end{array}$} & \multicolumn{2}{|c|}{ Responders } & \multirow{2}{*}{$\begin{array}{l}95 \% \text { confidence } \\
\text { interval (\%) }\end{array}$} & \multirow{2}{*}{$\begin{array}{c}\text { Median } \\
\text { survival } \\
\text { (months) }\end{array}$} \\
\hline & & & No. & $\%$ & & \\
\hline \multirow[t]{2}{*}{ Doxorubicin vs cyclophosphamide } & \multirow[t]{2}{*}{ Sorensen (1985) } & \multirow[t]{2}{*}{32} & 0 & 0 & $0-19$ & \multirow[t]{2}{*}{ na } \\
\hline & & & 0 & 0 & $0-19$ & \\
\hline \multirow[t]{2}{*}{ Doxorubicin+cyclophosphamide vs doxorubicin+cyclophosphamide+DTIC } & \multirow[t]{2}{*}{ Samson (1987) } & \multirow[t]{2}{*}{76} & 4 & 11 & $6-21$ & \multirow{2}{*}{$\begin{array}{l}7.5 \\
6.3\end{array}$} \\
\hline & & & 5 & 13 & $6-21$ & \\
\hline \multirow[t]{2}{*}{ Cisplatin+etoposide vs carboplatin } & \multirow[t]{2}{*}{ White SC (2000) } & \multirow[t]{2}{*}{25} & 1 & 8 & \multirow[t]{2}{*}{ na } & 4.7 \\
\hline & & & 0 & 0 & & 5.4 \\
\hline Onconase vs doxorubicin & Vogelzang (2000) & 154 & na & na & na & $\begin{array}{l}7.7 \\
8.2\end{array}$ \\
\hline Cisplatin vs cisplatin+pemetrexed & Vogelzang (2002) & 456 & na* & na* & $n a^{*}$ & na* \\
\hline
\end{tabular}

* Vogelzang N.: http://www.asco.org/asco/ascoMainConstructor/ I,47468,_. | |00235 I,00.asp?cat=General+Oncology.

na=not applicable.

et al, 1992; Icli et al, 1996; Krarup-Hansen, 1996; Andersen et al, 1999).

The older vinca alkaloids vinblastine, vincristine and vindesine have demonstrated no activity in the treatment of MPM (Kelsen et al, 1983; Boutin et al, 1987; Cowan et al, 1988; Martensson \& Sorenson, 1989). Likewise, poor results were shown with oral as well as IV etoposide (Tammilehto et al, 1994; Sahmoud et al, 1997).

The antifolates methotrexate and edatrexate have been the only single agents to produce comparatively better results. A Norwegian study reported a satisfactory response rate of $37 \%$ for high-dose methotrexate and a median survival of 11 months, for trial subjects with an epithelial subtype drawing a particular benefit from this chemotherapy option (Solheim et al, 1992). Sequential multicentre phase II studies conducted by the CALGB have evaluated the activity of the folate antagonist edatrexate, with and without leucovorin rescue. Edatrexate produced $25 \%$ overall response rates but proved to be relatively toxic. Leucovorin rescue in the control arm led to decreased toxicities, but may also have reduced the agent's efficacy (Kindler et al, 1999). Other antimetabolites like fluorouracil, dihydro-5-azacytidine (DHAC), dideazafolic acid and trimetrexate have shown minor or no activity in the treatment of 
MPM (Harvey et al, 1984; Vogelzang et al, 1994; Vogelzang et al, 1997; Samuels et al, 1998).

\section{Combination chemotherapy}

Doxorubicin-based regimens Doxorubicin is the anthracycline most frequently included in chemotherapeutic regimens. Initially encouraging response rates experienced with the doxorubicincisplatin combination in two phase II studies carried out in Germany (RR: 46\%) and Italy (RR: 25\%) (Henss et al, 1988; Ardizzoni et al, 1991) failed to be confirmed by a subsequent, randomised CALGB study of doxorubicin-cisplatin $v s$ mitomycin-cisplatin treatment (Chahinian et al, 1993). The doxorubicin-cisplatin doublet was only able to produce a $14 \%$ response rate and proved inferior to the mitomycin-cisplatin combination (RR: 26\%). Median survival duration from study entry was 7.7 and 8.8 months, respectively, with no significant differences between treatments. An Italian group administered the triplet doxorubicin-cisplatin-mitomycin to 24 MPM patients and reported a response rate of $20.9 \%$. Thus, the observed level of activity was similar to that obtained with the respective doublets (Pennucci et al, 1997).

The combination of doxorubicin, cisplatin and cyclophosphamide was tested by another prospective trial and produced a similar rate of response (Shin et al, 1995). A multi-institutional randomised study was designed to compare the activity of doxorubicin-cyclophosphamide with a triplet consisting of these agents in addition to dacarbazine. With a response rate of $13 \%$, the triplet did not prove superior to the doublet (RR: 11\%) (Samson et al, 1987).

The combination of doxorubicin and ifosfamide has also been investigated within two studies. One study giving doxorubicin and ifosfamide every 3 weeks achieved a response rate of $12.5 \%$ (Carmichael et al, 1989). Based on the same trial design, another group applied dose-escalated doxorubicin at $75 \mathrm{mg} \mathrm{m}^{-2}$, with a $32 \%$ response rate (Dirix et al, 1994). However, the 7-month median survival was poor and toxicity high, limiting the value of this schedule in the treatment of MPM.

Disappointing response rates have also been shown by the anthracyclines epirubicin and rubidazone as combined with ifosfamide and dacarbazine (Zidar et al, 1983; Magri et al, 1992).

Cisplatin-based regimens Apart from combinations with anthracyclines, cisplatin has also been tested in numerous other chemotherapy regimens. Three trials evaluated cisplatin combined with etoposide, showing response rates from 12 to $24 \%$ (Eisenhauer et al, 1988; Planting et al, 1995; White et al, 2000). The doublet combination of cisplatin and DHAC attained an insufficient response rate of $17.3 \%$ (Samuels et al, 1998). Moderate antitumour activity (RR: 25\%) was achieved by the doublet cisplatin-mitomycin in one arm of CALGB 8435, but median survival was poor (7.7 months) (Chahinian et al, 1993). A $25 \%$ response rate and a 13-month mean duration of response have been indicated for the cisplatin-vinblastine combination (Tsavaris et al, 1994). The cisplatin - mitomycin-C - vinblastine triplet did not prove to be superior to the doublets (RR: $23 \%$ ), yet produced a symptomatic benefit for $63 \%$ of the patients with particularly good response for pain (Middleton et al, 1998).

Likewise, other treatments combining such conventional cytotoxics as methotrexate with vincristine and mitomycin with vindesine have failed to prove effective (Dimitrov et al, 1982; Gridelli et al, 1992).

\section{NOVEL CYTOTOXICS}

\section{Anthracyclines}

\section{Liposomal anthracyclines}

Liposomal doxorubicin. Within a phase II study, the EORTC treated 35 patients with liposomal doxorubicin $\left(\right.$ Caelyx ${ }^{\circledR}$ ) at a dosage of $45 \mathrm{mg} \mathrm{m}^{-2}$ every 4 weeks (Baas et al, 2000). The drug was well tolerated, but the results were disappointing. Only two of the 31 patients $(6 \%)$ showed a partial response and the median survival was 13 months.

Similar results were reported by $\mathrm{Oh}$ et al, who administered $50 \mathrm{mg} \mathrm{m}^{-2}$ of liposomal doxorubicin (Doxil ${ }^{\mathbb{R}}$ ) every 4 weeks to 24 patients with pleural mesothelioma (Oh et al, 2000). With no objective responses and a median survival of only 37 weeks, the drug was considered inactive in this indication.

Liposomal daunorubicin. Liposomal daunorubicin (LD) was given to 13 patients at $120 \mathrm{mg} \mathrm{m}^{-2}$ every 3 weeks, but no responses were produced (Steele et al, 2001).

\section{Platinum compounds}

\section{ZD0473}

A phase II trial (Giaccone et al, 2001) assessed the efficacy of the new generation platinum compound ZD0473 at $120 \mathrm{mg} \mathrm{m}^{-2}$ on day 1 of a 21-day cycle in mesothelioma patients that had relapsed after previous platinum-based chemotherapy. Two of $10(20 \%)$ patients, experienced tumour shrinkage and five of $10(50 \%)$ subjects had stable disease.

\section{Topoisomerase interactive agents}

\section{Camptothecin analogues}

Irinotecan. The activity of single-agent irinotecan $\left(125 \mathrm{mg} \mathrm{m}^{-2}\right.$ given weekly for 4 weeks, every 6 weeks) in malignant mesothelioma was investigated by the CALGB (Kindler et al, 2000). In 28 patients evaluable for analysis, no complete or partial responses were observed and the median overall survival was 7.9 months, indicating that irinotecan, at least in this dose and schedule, had no antitumor activity and considerable toxicity (leucopenia, neutropenia, diarrhoea).

Furthermore, the combination of irinotecan and cisplatin was evaluated by a Japanese group (Nakano et al, 1999). A total of 15 chemonaive MPM patients were treated with irinotecan at $60 \mathrm{mg} \mathrm{mg}^{-2}$ on days 1,8 and 15 and cisplatin at $60 \mathrm{mg} \mathrm{m}^{-2}$ on day 1 , repeated every 28 days. A response rate of $26.7 \%$ (four partial responses) was observed and the median survival after chemotherapy was 28.3 weeks. In contrast to the trial conducted by the CALGB, Nakano et al reported definite activity with only mild toxicity of this combination regimen and concluded that it warrants further clinical evaluation.

Recently, Verschraegen et al (2001) published retrospective data of the same combination in 10 patients with peritoneal mesothelioma. Six courses of irinotecan $50 \mathrm{mg} \mathrm{m}^{-2}$ (day 1, 8 and 15) and cisplatin $50 \mathrm{mg} \mathrm{m}^{-2}$ (day 1) were administered every 4 weeks, either intraperitoneally or intravenously, and were well tolerated. The authors reported that $70 \%$ of the patients improved on treatment. Owing to the observed clinical benefit, a phase II trial is currently planned.

Topotecan. In order to evaluate the efficacy and toxicity of the camptothecin analogue topotecan in the treatment of MPM, the North Central Cancer Treatment Group treated 22 MPM patients with topotecan $1.5 \mathrm{mg} \mathrm{m}^{-2}$ daily for 5 days at 3-week intervals. 18 patients $(86 \%)$ experienced grade 3 or 4 neutropenia. There were no objective responses seen and the median survival for all patients was 230 days (Maksymiuk et al, 1998).

\section{Antimicrotubule agents}

\section{Vinca alcaloids}

Vinorelbine. Steele et al (2000) administered vinorelbine to 64 patients with MPM at a weekly $30 \mathrm{mg} \mathrm{m}^{-2}$ dose for 6 weeks. A response rate of $21 \%$ ( 12 out of 64 patients) was observed and $63 \%$ of patients experienced disease stabilisation. Furthermore, the 
patients' quality of life was increased with respect to lung-related symptoms and physical well-being in general.

The same study group conducted a trial to evaluate the activity of vinorelbine at $30 \mathrm{mg} \mathrm{m}^{-2}$ on days 1 and 8 and oxaliplatin $130 \mathrm{mg} \mathrm{m}^{-2}$ on day 1 every 3 weeks in $21 \mathrm{MPM}$ patients (Steele et al, 2000). Only two partial responses had been observed and toxicity had been significant. These inferior results could perhaps result from the large number of stage IV patients, the higher proportion of less favorable subtypes, and the inclusion of several participants showing a low performance status. At any rate, the addition of oxaliplatin to vinorelbine seems to bring no advantage, thus discouraging further studies in this doublet.

Recently, a British randomised phase III study has been initiated, comparing the efficacy of single-agent vinorelbine $\left(30 \mathrm{mg} \mathrm{m}^{-2}\right.$ up to $60 \mathrm{mg} \mathrm{m}^{-2}$ ) vs MPV (mitomycin $8 \mathrm{mg} \mathrm{m}^{-2}$, vinblastin $6 \mathrm{mg} \mathrm{m}^{-2}$, cisplatin $50 \mathrm{mg} \mathrm{m}^{-2}$ ) $v s$ active best supportive care alone.

\section{Taxanes}

Paclitaxel. A total of 25 patients with MPM were given paclitaxel intravenously at a dose of $200 \mathrm{mg} \mathrm{m}^{-2}$ as a $3 \mathrm{~h}$ infusion every 3 weeks in a phase II study conducted by the EORTC Lung Cancer Cooperative Group (van Meerbeeck et al, 1996). No major objective responses were seen and the median survival time was only 39 weeks.

These disappointing results were confirmed by the CALGB, which administered paclitaxel at a slightly higher dose of $250 \mathrm{mg} \mathrm{m}^{-2}$, given as a 24-hour infusion every 3 weeks plus filgastrim (G-CSF) support to 35 patients with MPM (Vogelzang et al, 1999). Only three (9\%) regressions of evaluable disease were observed and the median survival was 5 months.

Fizazi et al (2000) conducted a phase II study of paclitaxel $\left(200 \mathrm{mg} \mathrm{m}^{-2}\right)$ and cisplatin $\left(100 \mathrm{mg} \mathrm{m}^{-2}\right)$, given to 18 patients on day 1 every 3 weeks. With only one partial response and a response rate of $6 \%$, the paclitaxel-cisplatin doublet was considered ineffective and the trial was stopped early.

Bednar (1999) evaluated the combination of paclitaxel at $175 \mathrm{mg} \mathrm{m}^{-2}$ and carboplatin at an AUC of 5-6 in seven patients with malignant mesothelioma and reported more encouraging results. One patient with peritoneal malignant mesothelioma had a pathologically proven CR for a duration of 20 months. The overall median survival was 15 months from diagnosis and 12 months from the onset of treatment.

Docetaxel. The Eastern Cooperative Oncology Group assigned 19 patients with malignant mesothelioma to a phase II study of docetaxel $100 \mathrm{mg} \mathrm{m}^{-2}$, administered every 21 days. Only one patient achieved a partial response, with an overall response rate of $5 \%$. The study group thus concluded that docetaxel was not effective in the treatment of malignant mesothelioma (Belani et al, 1999).

Vorobiof et al (2000), who also evaluated the activity of docetaxel using the same treatment schedule, reported only three partial remissions and six minor responses $(25 \%$ or less reduction in tumour burden) in $22 \mathrm{MPM}$ patients with median survival barely exceeding 12 months.

A clinical study further tested docetaxel at $60 \mathrm{mg} \mathrm{m}^{-2}$ in combination with irinotecan at $190 \mathrm{mg} \mathrm{m}^{-2}$ on day 1 of a 3-weekly cycle in 15 MPM patients (Knuuttila et al, 2000). No objective responses were achieved, and median survival was 8.5 months only. The study was finally discontinued owing to high toxicity and deficient activity levels.

\section{Antimetabolites}

\section{Antifolates}

Raltitrexed. The EORTC has recently completed a phase II study of the quinazoline antifolate raltitrexed (ZD1694, Tomudex) at $3 \mathrm{mg} \mathrm{m}^{-2}$ as a single agent in the treatment of malignant mesothelioma, which is now in final analysis.
From 1999 to 2000, the Institut Gustave Roussy has treated 70 patients with a combination of raltitrexed $\left(3 \mathrm{mg} \mathrm{m}^{-2}\right)$ and oxaliplatin $\left(130 \mathrm{mg} \mathrm{m}^{-2}\right)$. Preliminary results show an encouraging response rate of $25 \%$ (14 of 57 patients evaluable for efficacy) and acceptable toxicity (Fizazi et al, 2000).

Based on these promising results, the EORTC initiated a randomised phase III study, evaluating the efficacy of the doublet raltitrexed $\left(3 \mathrm{mg} \mathrm{m}^{-2}\right)-$ cisplatin $\left(80 \mathrm{mg} \mathrm{m}^{-2}\right)$ vs cisplatin $\left(80 \mathrm{mg} \mathrm{m}^{-2}\right)$ alone.

Pemetrexed. A phase I study conducted in 1999 first investigated the activity of the multitargeted antifolate pemetrexed (LY231514, ALIMTA $^{\mathbb{R}}$ ) combined with cisplatin in patients presenting with solid tumours (Thodtmann et al, 1999). Of 11 mesothelioma patients evaluable for analysis, five experienced a partial remission (RR: 45\%).

These promising data resulted in the largest phase III study ever conducted in patients with MPM, which was initiated in March 1999. The results of this single-blind trial were first presented at the ASCO annual meeting in May 2002. A total of 456 patients were randomised to receive either cisplatin-pemetrexed (cisplatin $75 \mathrm{mg} \mathrm{m}^{-2}$ and pemetrexed $500 \mathrm{mg} \mathrm{m}^{-2}$ on day 1, every 21 days) or cisplatin monotherapy in the control group. The combination of pemetrexed - cisplatin resulted in superior median overall survival, response rate, lung function and subjective quality-of-life measures (Vogelzang $\mathrm{N}$ http://www.asco.org/asco/ascoMainConstructor $/ 1,47468,12 \mid 002351,00$.asp? cat = General+Oncology). The principal investigator concluded that based on these very promising data, pemetrexed - cisplatin should now be considered standard front-line therapy for patients with MPM.

Another phase I pemetrexed study demonstrated clinical activity in combination with carboplatin. A total of 27 patients were treated with various dose levels of pemetrexed and carboplatin on day 1 of a 21-day schedule (Hughes et al, 2002). In 25 evaluable patients, eight $(32 \%)$ achieved a partial remmission and 14 experienced stable disease at various dose levels. Furthermore, a symptomatic improvement was documented in 19 cases.

A two-stage phase II trial has just been completed by Scagliotti and collaborators, investigating single-agent pemetrexed in the treatment of MPM. A total of 62 patients were given pemetrexed at $500 \mathrm{mg} \mathrm{m}^{-2}$ on day 1 , every 3 weeks. Scagliotti et al (2001) reported a response rate of $14.5 \%$ and a median survival of 10.7 months.

Furthermore, a randomised phase III trial comparing pemetrexed plus best supportive care $v s$ best supportive care alone in previously treated patients with MPM is currently ongoing.

\section{Nucleoside analogues}

Gemcitabine. The activity of single-agent gemcitabine at $1250 \mathrm{mg} \mathrm{m}^{-2}$ on days 1,8 and 15 on a 28-day schedule was evaluated by the EORTC-Lung Cancer Group in 27 chemotherapynaive subjects with MPM (van Meerbeeck et al, 1999). Two partial responses were achieved for an overall response rate of $7 \%$. An additional $56 \%$ experienced disease stabilisation and overall median survival was 8 months.

The CALGB administered high-dose gemcitabine at $1500 \mathrm{mg} \mathrm{m}^{-2}$ on days 1,8 and 15 in a 28-day cycle to 17 participants (Kindler et al, 2001). Only one minor regression and six cases of stable disease were reported in 13 assessable patients, with an overall median survival of 4.1 months. In contrast to these data, Bischoff et al (1998) reported an encouraging response rate of $31 \%(5 / 16)$ with the same dose and schedule as the van Meerbeck study (gemcitabine $1250 \mathrm{mg} \mathrm{m}^{-2}$ on days 1,8 and 15 , every 28 days). Furthermore, seven additional patients reported a symptom relief via decreased pain or dyspnoea.

An Australian study group evaluated the doublet gemcitabinecisplatin in 21 patients presenting with advanced MPM (Byrne et al, 1999). The subjects received gemcitabine at $1000 \mathrm{mg} \mathrm{m}^{-2}$ on day 1 , 8 and 15 and cisplatin at $100 \mathrm{mg} \mathrm{m}^{-2}$ on day 1 of a 28-day cycle. This combination chemotherapy produced an encouraging 
response rate of $47.6 \%$ and an overall survival of 41 weeks. Furthermore, nine of 10 responding patients experienced significant relief of chest pain and dyspnoea. Subsequently, a multicentre study was initiated, evaluating the same chemotherapy regimen in 53 MPM patients (Novak et al, 2002). A response rate of $33 \%$ was achieved and the median survival time was 11.2 months. Response to treatment was accompanied by significantly improved global quality of life and respiratory function.

Contrary to the Australian trials, however, only four (15\%) of 22 assessable subjects experienced a partial response within a European multicentre phase II study (Van Haarst et al, 2000) of gemcitabine at $1250 \mathrm{mg} \mathrm{m}^{-2}$ on days 1 and 8 , in addition to cisplatin at $80 \mathrm{mg} \mathrm{m}^{-2}$ on day 1 . The discrepancy between these studies may possibly result from the different treatment schedules, patient selection criteria and methodology applied in treatment evaluation.

In turn, Aversa et al (1998) on evaluated the activity of the gemcitabine - carboplatin combination. A total of 20 patients were given gemcitabine at $1000 \mathrm{mg} \mathrm{m}^{-2}$ on days 1,8 and 15 and carboplatin $(A U C=5)$ on day 1 , every 28 days for a median of 4.5 cycles. In 18 assessable subjects, a response rate of $16 \%$ and an 8.6-month median survival rate was achieved.

Recently, investigators at the University of Chicago have initiated a multicenter, randomised phase II trial of cisplatingemcitabine and the vascular endothelial growth factor (VEGF) inhibitor bevacizumab, which has shown preliminary evidence of activity in MPM.

\section{CONCLUSION}

With rates of objective tumour regression ranging from 10 to $30 \%$ for cytotoxic monotherapy, diffuse pleural mesothelioma was considered to date to be widely chemoresistant. The most favourable responses to conventional chemotherapeutic agents were reported by the antimetabolites methotrexate and edatrexate.

In the past few years, a number of novel cytotoxic agents have been introduced into clinical oncology, the activity of which has also been tested in MPM therapy. Initial results produced by monotherapy based on new antimetabolites, along with platin combinations, provide encouragement. Preliminary results of the raltitrexed - oxaliplatin combination have shown promising activity. Single-agent gemcitabine and the drug combined with cisplatin appear to decrease symptoms associated with tumor load. In particular, pemetrexed with cisplatin has demonstrated superior median overall survival, response rate, lung function and qualityof-life measures in the largest randomised trial in MPM. These promising data suggest that finally effective chemotherapy exists for this aggressive disease and that pemetrexed-cisplatin will become a new systemic therapy standard.

\section{REFERENCES}

Aisner J, Wiernik PH (1981) Chemotherapy in the treatment of malignant mesothelioma. Semin Oncol 8: $335-343$

Alberts AS, Falkson G, Van Zyl L (1988) Malignant pleural mesothelioma: phase II pilot study of ifosfamide and mesna. J Natl Cancer Inst 80: $698-700$

Andersen MK, Krarup-Hansen A, Martensson G, Winther-Nielsen H, Thylen A, Damgaard K, Olling S, Wallin J (1999) Ifosfamide in malignant mesothelioma: a phase II study. Lung Cancer 24: 39-43

Antman KH, Blum RH, Greenberger JS, Flowerdew G, Skarin AT, Canellos GP (1980) Multimodality therapy for malignant mesothelioma based on a study of natural history. Am J Med 68: $356-362$

Antman KH, Corson JM. (1985) Benign and malignant pleural mesothelioma. Clin Chest Med 6: 127 - 140

Ardizzoni A, Rosso R, Salvati F, Fusco V, Cinquegrana A, De Palma M, Serrano J, Pennucci MC, Soresi E, Crippa M et al (1991) Activity of doxorubicin and cisplatin combination chemotherapy in patients with diffuse malignant pleural mesothelioma. An Italian Lung Cancer Task Force (FONICAP) Phase II study. Cancer 67: 2984-2987

Aversa SL, Crcuri C, DePangher V et al (1998) Carboplatin and Gemcitabine chemotherapy for malignant pleural mesothelioma (MPM): A phase II study of the GSTPV. Ann of Oncol 9: 117

Baas P, van Meerbeeck J, Groen H, Schouwink H, Burgers S, Daamen S, Giaccone G (2000) Caelyx in malignant mesothelioma: a phase II EORTC study. Ann Oncol 11: $697-700$

Bajorin D, Kelsen D, Mintzer DM (1987) Phase II trial of mitomycin in malignant mesothelioma. Cancer Treat Rep 71: 857 - 858

Bednar ME, Chahinian P (1999) Paclitaxel and carboplatin for malignant mesothelioma. Ann Meet Am Soc Clin Oncol A1916 18: 496a

Belani CP, Adak S, Aisner S, Stella PJ, Levitan N, Johnson DH (1999) Docetaxel for malignant mesothelioma: phase II study of the eastern Cooperative Oncology Group (ECOG 2595). Proc Am Soc Clin Oncol 1999 A1829, Vol 18, p.p. 474a

Bischoff HG, Manegold C, Knopp M, Blatter J, Drings P (1998) Gemcitabine $\left(\right.$ Gemzar $\left.^{\circledR}\right)$ may reduce tumor load and tumor associated symptoms in malignant pleural mesothelioma. Proc Ann Meet Am Soc Clin Oncol 17; A1784

Bissett D, Macbeth FR, Cram I (1991) The role of palliative radiotherapy in malignant mesothelioma. Clin Oncol ( $R$ Coll Radiol) 3: 315-317

Boutin C, Irisson M, Guerin JC, Roegel E, Paramelle B, Brambilla C, Jeannin L, Dabouis G, Le Caer H, Viallat JR (1987) Phase II trial of vindesine in malignant pleural mesothelioma. Cancer Treat Rep 71: $205-206$
Boutin C, Schlesser M, Frenay C, Astoul P (1998) Malignant pleural mesothelioma. Eur Respir J 12: 972 - 981

Breau JL, Boaziz C, Morere JJF (1991) Cobination therapy with cisplatinum, adramycin, bleomycin and mitomycin $\mathrm{C}$ plus systemic and intra-pleural hyaluronidase in 25 consecitive cases of stages II, III pleural mesothelioma. Presented at the first International Mesothelioma Conference, Paris, France

Byrne MJ, Davidson JA, Musk AW, Dewar J, van Hazel G, Buck M, de Klerk NH, Robinson BW (1999) Cisplatin and gemcitabine treatment for malignant mesothelioma: a phase II study. J Clin Oncol 17: $25-30$

Carmichael J, Cantwell BM, Harris AL (1989) A phase II trial of ifosfamide/ mesna with doxorubicin for malignant mesothelioma. Eur J Cancer Clin Oncol 25: $911-912$

Chahinian AP, Antman K, Goutsou M, Corson JM, Suzuki Y, Modeas C, Herndon II JE, Aisner J, Ellison RR, Leone L et al (1993) Randomised phase II trial of cisplatin with mitomycin or doxorubicin for malignant mesothelioma by the Cancer and Leukemia Group B. J Clin Oncol 11: $1559-1565$

Colbert N, Vannetzel JM, Izrael V, Schlienger M, Milleron B, Blanchon F, Herman D, Akoun G, Roland J, Chatelet F et al (1985) A prospective study of detorubicin in malignant mesothelioma. Cancer 56: 2170 - 2174

Cowan JD, Green S, Lucas J, Weick JK, Balcerzak SP, Rivkin SE, Coltman CA, Baker LH (1988) Phase II trial of five day intravenous infusion vinblastine sulfate in patients with diffuse malignant mesothelioma: a Southwest Oncology Group study. Invest New Drugs 6: $247-248$

Curran D, Sahmoud T, Therasse P, van Meerbeeck J, Postmus PE, Giaccone G (1998) Prognostic factors in patients with pleural mesothelioma: the European Organization for Research and Treatment of Cancer experience. J Clin Oncol 16: $145-152$

Dimitrov NV, Egner J, Balcueva E, Suhrland LG (1982) High-dose methotrexate with citrovorum factor and vincristine in the treatment of malignant mesothelioma. Cancer 50: 1245 - 1247

Dirix LY, van Meerbeeck J, Schrijvers D, Corthouts B, Prove A, van Marck E, Vermeire P, van Oosterom AT (1994) A phase II trial of dose-escalated doxorubicin and ifosfamide/mesna in patients with malignant mesothelioma. Ann Oncol 5: $653-655$

Eisenhauer EA, Evans WK, Murray N, Kocha W, Wierzbicki R, Wilson K (1988) A phase II study of VP-16 and cisplatin in patients with unresectable maignant mesothelioma. An NCI Canada Clinical Trials Group Study. Invest New Drugs 6: $327-329$ 
Eisenhauer EA, Evans WK, Raghavan D, Desmeules MJ, Murray NR, StuartHarris R, Wilson KS (1986) Phase II study of mitoxantrone in patients with mesothelioma: a National Cancer Institute of Canada Clinical Trials Group Study. Cancer Treat Rep 70: $1029-1030$

Falkson G, Hunt M, Borden EC, Hayes JA, Falkson CI, Smith TJ (1992) An extended phase II trial of ifosfamide plus mesna in malignant mesothelioma. Invest New Drugs 10: $337-343$

Fizazi K, Caliandro R, Soulie P, Fandi A, Daniel C, Bedin A, Doubre H, Viala J, Rodier J, Trandafir L, Le Chevalier T, Cvitkovic E, Armand J, Ruffie P (2000) Combination raltitrexed (Tomudex(R))-oxaliplatin: a step forward in the struggle against mesothelioma? The Institut Gustave Roussy experience with chemotherapy and chemo-immunotherapy in mesothelioma. Eur J Cancer 36: 1514 - 1521

Giaccone G, O’Brien M, Byrne MJ, Van Steenkiste J, Cosaert J (2001) Phase II Trial of ZD0473 in Patients with Mesothelioma Relapsing After One Prior Chemotherapy Regimen. Proc Ann. Meet Am Soc Clin Oncol A2781 20: $257 b$

Gridelli C, Pepe R, Airoma G, Incoronato P, Rossi A, Palazzolo G, Bianco AR (1992) Mitomycin C and vindesine: an ineffective combination chemotherapy in the treatment of malignant pleural mesothelioma. Tumori 78: $380-382$

Harvey VJ, Slevin ML, Ponder BA, Blackshaw AJ, Wrigley PF (1984) Chemotherapy of diffuse malignant mesothelioma. Phase II trials of single-agent 5-fluorouracil and adriamycin. Cancer 54: 961 - 964

Henss H, Fiebig HH, Schildge J, Arnold H, Hasse J (1988) Phase-II study with the combination of cisplatin and doxorubicin in advanced malignant mesothelioma of the pleura. Onkologie 11: 118-120

Hilaris BS, Nori D, Kwong E, Kutcher GJ, Martini N (1984) Pleurectomy and intraoperative brachytherapy and postoperative radiation in the treatment of malignant pleural mesothelioma. Int J Radiat Oncol Biol Phys 10: $325-331$

Hughes A, Calvert P, Azzabi A, Plummer A, Johnsons R, Rusthoven R, Griffin M, Fishwick K, Boddy AV, Verril M, Calvert H (2002) Phase I clinical and pharmacokinetic study of pemetrexed and carboplatin in patients with malignant pleural mesothelioma. J Clin Oncology 20: 3533 3544

Icli F, Karaoguz H, Hasturk S, Kurt B, Akbulut H, Dincol D, Demirkazik A, Cay F, Akyar S (1996) Two dose levels of ifosfamide in malignant mesothelioma. Lung Cancer 15: 207-213

Kaukel E, Koschel G, Gatzemeyer U, Salewski E (1990) A phase II study of pirarubicin in malignant pleural mesothelioma. Cancer 66: 651 - 654

Kelsen D, Gralla R, Cheng E, Martini N (1983) Vindesine in the treatment of malignant mesothelioma: a phase II study. Cancer Treat Rep 67: 821 - 822

Kindler HL, Belani CP, Herndon II JE, Vogelzang NJ, Suzuki Y, Green MR (1999) Edatrexate (10-ethyl-deaza-aminopterin) (NSC \#626715) with or without leucovorin rescue for malignant mesothelioma. Sequential phase II trials by the cancer and leukemia group B. Cancer 86: 1985-1991

Kindler HL, Herndon JE, Vogelzang NJ, Green MR. (2000). CPT-11 in Malignant Mesothelioma: A Phase II Trial by the Cancer and Leukemia Group B (CALGB 9733). Proc Ann. Meet Am Soc Clin Oncol 27: A1978. Vol. 19, pp. 505a

Kindler HL, Millard F, Herndon II JE, Vogelzang NJ, Suzuki Y, Green MR (2001) Gemcitabine for malignant mesothelioma: A phase II trial by the Cancer and Leukemia Group B. Lung Cancer 31: 311-317

Knuuttila A, Ollikainen T, Halme M, Mali P, Kivisaari L, Linnainmaa K, Jekunen A, Mattson K (2000) Docetaxel and irinotecan (CPT-11) in the treatment of malignant pleural mesothelioma-a feasibility study. Anticancer Drugs 11: $257-261$

Krarup-Hansen A (1996) Studies concerning high dose ifosfamide to patients suffering from malignant mesothelioma. Lung Cancer 16: $101-102$

Kutcher GJ, Kestler C, Greenblatt D, Brenner H, Hilaris BS, Nori D (1987) Technique for external beam treatment for mesothelioma. Int J Radiat Oncol Biol Phys 13: $1747-1752$

Linden CJ, Mercke C, Albrechtsson U, Johansson L, Ewers SB (1996) Effect of hemithorax irradiation alone or combined with doxorubicin and cyclophosphamide in 47 pleural mesotheliomas: a nonrandomised phase II study. Eur Respir J 9: 2565 - 2572

Magri MD, Foladore S, Veronesi A, Serra C, Nicotra M, Tommasi M, Grandi G, Monfardini S, Bianchi C (1992) Treatment of malignant mesothelioma with epirubicin and ifosfamide: a phase II cooperative study. Ann Oncol 3: $237-238$

Magri MD, Veronesi A, Foladore S, De Giovanni D, Serra C, Crismancich F, Tuveri G, Nicotra M, Tommasi M, Morassut S et al (1991) Epirubicin in the treatment of malignant mesothelioma: a phase II cooperative study.
The North-Eastern Italian Oncology Group (GOCCNE)-Mesothelioma Committee. Tumori 77: 49-51

Maksymiuk AW, Marschke Jr RF, Tazelaar HD, Grill J, Nair S, Marks RS, Brooks BJ, Mailliard JA, Burton GM, Jett JR (1998) Phase II trial of topotecan for the treatment of mesothelioma. Am J Clin Oncol 21: $610-613$

Martensson G, Sorenson S (1989) A phase II study of vincristine in malignant mesothelioma-a negative report. Cancer Chemother Pharmacol 24: $133-134$

Mattson K, Giaccone G, Kirkpatrick A, Evrard D, Tammilehto L, van Breukelen FJ, Planteydt HT, van Zandwijk N (1992) Epirubicin in malignant mesothelioma: a phase II study of the European Organization for Research and Treatment of Cancer Lung Cancer Cooperative Group. $J$ Clin Oncol 10: $824-828$

Mbidde EK, Harland SJ, Calvert AH, Smith IE (1986) Phase II trial of carboplatin (JM8) in treatment of patients with malignant mesothelioma. Cancer Chemother Pharmacol 18: 284-285

Middleton GW, Smith IE, O'Brien ME, Norton A, Hickish T, Priest K, Spencer L, Ashley S. (1998) Good symptom relief with palliative MVP (mitomycin-C, vinblastine and cisplatin) chemotherapy in malignant mesothelioma. Ann Oncol 9: 269-273

Nakano T, Chahinian AP, Shinjo M, Togawa N, Tonomura A, Miyake M, Ninomiya K, Yamamoto T, Higashino K (1999) Cisplatin in combination with irinotecan in the treatment of patients with malignant pleural mesothelioma: a pilot phase II clinical trial and pharmacokinetic profile. Cancer 85: $2375-2384$

Novak A, Byrne M, Williamson R (2002) Multicentre phase II study of cisplatin and gemcitabine for malignant mesothelioma. Br J Cancer 87: $491-496$

Oh Y, Perez-Soler R, Fossella FV, Glisson BS, Kurie J, Walsh GL, Truong M, Shin DM (2000) Phase II study of intravenous Doxil in malignant pleural mesothelioma. Invest New Drugs 18: $243-245$

Pass HI, Temeck BK, Kranda K, Steinberg SM, Feuerstein IR (1998) Preoperative tumor volume is associated with outcome in malignant pleural mesothelioma. J Thorac Cardiovasc Surg 115: 310 - 317 discussion $317-318$

Pennucci MC, Ardizzoni A, Pronzato P, Fioretti M, Lanfranco C, Verna A, Giorgi G, Vigani A, Frola C, Rosso R (1997) Combined cisplatin, doxorubicin, and mitomycin for the treatment of advanced pleural mesothelioma: a phase II FONICAP trial. Italian Lung Cancer Task Force. Cancer 79: $1897-1902$

Pinto C, Marino A, Guaraldi M, Melotti B, Piana E, Martoni A, Pannuti F (2001) Combination chemotherapy with mitoxantrone, methotrexate, and mitomycin (MMM regimen) in malignant pleural mesothelioma: a phase II study. Am J Clin Oncol 24(2): $143-147$

Planting AS, van der Burg ME, Goey SH, Schellens JH, van den Bent MJ, de Boer-Dennert M, Stoter G, Verweij J (1995) Phase II study of a short course of weekly high-dose cisplatin combined with long-term oral etoposide in pleural mesothelioma. Ann Oncol 6: 613-615

Raghavan D, Gianoutsos P, Bishop J, Lee J, Young I, Corte P, Bye P, McCaughan B (1990) Phase II trial of carboplatin in the management of malignant mesothelioma. J Clin Oncol 8: 151-154

Rusch VW, Venkatraman E (1996) The importance of surgical staging in the treatment of malignant pleural mesothelioma. J Thorac Cardiovasc Surg 111: 815 - 825 discussion $825-826$

Sahmoud T, Postmus PE, van Pottelsberghe C, Mattson K, Tammilehto L, Splinter TA, Planting AS, Sutedja T, van Pawel J, van Zandwijk N, Baas P, Roozendaal KJ, Schrijver M, Kirkpatrick A, Van Glabbeke M, Ardizzoni A, Giaccone G (1997) Etoposide in malignant pleural mesothelioma: two phase II trials of the EORTC Lung Cancer Cooperative Group. Eur J Cancer 33: 2211 - 2215

Samson MK, Wasser LP, Borden EC, Wanebo HJ, Creech RH, Phillips M, Baker LH (1987) Randomised comparison of cyclophosphamide, imidazole carboxamide, and adriamycin versus cyclophosphamide and adriamycin in patients with advanced stage malignant mesothelioma: a Sarcoma Intergroup Study. J Clin Oncol 5: 86-91

Samuels BL, Herndon II JE, Harmon DC, Carey R, Aisner J, Corson JM, Suzuki Y, Green MR, Vogelzang NJ (1998) Dihydro-5-azacytidine and cisplatin in the treatment of malignant mesothelioma: a phase II study by the Cancer and Leukemia Group B. Cancer 82: $1578-1584$

Scagliotti G, Shin D, Kindler H, Johnson D, Keppler U (2001) Phase II Study of ALIMTA (pemetrexed disodium, MTA) Single Agent in Patients with Malignant Pleural Mesothelioma. Eur J Cancer 37 (Suppl. 6): 20 
Shin DM, Fossella FV, Umsawasdi T, Murphy WK, Chasen MH, Walsh G, Komaki R, McMurtrey MJ, Hong WK (1995) Prospective study of combination chemotherapy with cyclophosphamide, doxorubicin, and cisplatin for unresectable or metastatic malignant pleural mesothelioma. Cancer 76: 2230 - 2236

Solheim OP, Saeter G, Finnanger AM, Stenwig AE (1992) High-dose methotrexate in the treatment of malignant mesothelioma of the pleura. A phase II study. Br J Cancer 65: $956-960$

Sorensen PG, Bach F, Bork E, Hansen HH (1985) Randomised trial of doxorubicin versus cyclophosphamide in diffuse malignant pleural mesothelioma. Cancer Treat Rep 69: $1431-1432$

Soubra M, Dunscombe PB, Hodson DI, Wong G (1990) Physical aspects of external beam radiotherapy for the treatment of malignant pleural mesothelioma. Int J Radiat Oncol Biol Phys 18: $1521-1527$

Sridhar KS, Hussein AM, Feun LG, Zubrod CG (1989) Activity of pirarubicin ( $4^{\prime}-0$-tetrahydropyranyladriamycin) in malignant mesothelioma. Cancer, 63: $1084-1091$

Steele JP, O'Doherty CA, Shamash J, Evans MT, Gower NH, Tischkowitz MD, Rudd RM (2001) Phase II trial of liposomal daunorubicin in malignant pleural mesothelioma. Ann Oncol 12: 497 - 499

Steele JP, Rudd RM (2000) Malignant mesothelioma: predictors of prognosis and clinical trials. Thorax 55: $725-726$

Steele JP, Shamash J, Evans MT, Gower NH, Tischkowitz MD, Rudd RM (2000) Phase II study of vinorelbine in patients with malignant pleural mesothelioma. J Clin Oncol 18: 3912 - 3917

Tammilehto L, Maasilta P, Mantyla M, Salo J, Mattson K (1994) Ora etoposide in the treatment of malignant mesothelioma. A phase II study. Ann Oncol 5: 949 - 950

Thodtmann R, Depenbrock H, Blatter J, Johnson RD, van Oosterom A, Hanauske AR (1999) Preliminary results of a phase I study with MTA (LY231514) in combination with cisplatin in patients with solid tumors. Semin Oncol 26: 89-93

Tsavaris N, Mylonakis N, Karvounis N, Bacoyiannis C, Briasoulis E, Skarlos D, Pavlidis N, Stamatelos G, Kosmidis P (1994) Combination chemotherapy with cisplatin-vinblastine in malignant mesothelioma. Lung Cancer 11: 299-303

van Breukelen FJ, Mattson K, Giaccone G, van Zandwijk N, Planteydt HT, Kirkpatrick A, Dalesio O (1991) Mitoxantrone in malignant pleural mesothelioma: a study by the EORTC Lung Cancer Cooperative Group. Eur J Cancer 27: 1627 - 1629

Van Haarst JW, Burgers JA, Manegold CH et al (2000) Multicenter phase II study of gemcitabine and cisplatin in malignant pleural mesothelioma (MPM). Program and abstracts of the 9th World Conference on Lung Cancer; September $11-15$, Tokyo, Japan. Abstract 56

van Meerbeeck JP, Baas P, Debruyne C, Groen HJ, Manegold C, Ardizzon A, Gridelli C, van Marck EA, Lentz M, Giaccone G (1999) A Phase II study of gemcitabine in patients with malignant pleural mesothelioma.
European Organization for Research and Treatment of Cancer Lung Cancer Cooperative Group. Cancer 85: $2577-2582$

van Meerbeeck J, Debruyne C, van Zandwijk N, Postmus PE, Pennucci MC, van Breukelen F, Galdermans D, Groen H, Pinson P, van Glabbeke M, van Marck E, Giaccone G (1996) Paclitaxel for malignant pleural mesothelioma: a phase II study of the EORTC Lung Cancer Cooperative Group. Br J Cancer 74: 961 - 963

Verschraegen C, Le D, Kudelka A, Kavanagh J, Hunt K (2001) Cisplatin and Irinotecan (CPT-11) for Peritoneal Mesothelioma. Proc Ann Meet Am Soc Clin Oncol A2110 20: 90

Vogelzang NJ, Goutsou M, Corson JM, Suzuki Y, Graziano S, Aisner J, Cooper MR, Coughlin KM, Green MR (1990) Carboplatin in malignant mesothelioma: a phase II study of the Cancer and Leukemia Group B. Cancer Chemother Pharmacol 27: 239-242

Vogelzang NJ, Herndon II JE, Cirrincione C, Harmon DC, Antman KH, Corson JM, Suzuki Y, Citron ML, Green MR (1997) Dihydro-5azacytidine in malignant mesothelioma. A phase II trial demonstrating activity accompanied by cardiac toxicity. Cancer and Leukemia Group B. Cancer 79: 2237 - 2242

Vogelzang NJ, Herndon II JE, Miller A, Strauss G, Clamon G, Stewart FM, Aisner J, Lyss A, Cooper MR, Suzuki Y, Green MR (1999) High-dose paclitaxel plus G-CSF for malignant mesothelioma: CALGB phase II study 9234. Ann Oncol 10: $597-600$

Vogelzang NJ, Weissman LB, Herndon II JE, Antman KH, Cooper MR, Corson JM, Green MR (1994) Trimetrexate in malignant mesothelioma: A Cancer and Leukemia Group B Phase II study. J Clin Oncol 12: 1436 1442

Vorobiof DA, Chasen MR, Abratt R, Rapoport B, Cronje N, Fourie L, McMichael G, Hacking D (2000) Taxotere in malignant pleural mesothelioma. A Phase II clinical trial. Program and abstracts of the 9th World Conference on Lung Cancer; September 11 - 15, Tokyo, Japan. Abstract 58.

White SC, Anderson H, Jayson GC, Ashcroft L, Ranson M, Thatcher N (2000) Randomised phase II study of cisplatin-etoposide versus infusional carboplatin in dvanced non-small-cell lung cancer and mesothelioma. Ann Oncol 11: 201 - 206

Zidar BL, Benjamin RS, Frank J, Lane M, Baker LH (1983) Combination chemotherapy for advanced sarcomas of bone and mesothelioma utilizing rubidazone and DTIC: a Southwest Oncology Group Study. Am J Clin Oncol 6: $71-74$

Zidar BL, Green S, Pierce HI, Roach RW, Balcerzak SP, Militello L (1988) A phase II evaluation of cisplatin in unresectable diffuse malignant mesothelioma: a Southwest Oncology Group Study. Invest New Drugs 6: 223-226

Zidar BL, Metch B, Balcerzak SP, Pierce HI, Militello L, Keppen MD, Berenberg JL (1992) A phase II evaluation of ifosfamide and mesna in unresectable diffuse malignant mesothelioma. A Southwest Oncology Group study. Cancer 70: $2547-2551$ 